\title{
A facile synthesis of mono dispersed spherical silver doped bioactive glass nanoparticle
}

\author{
Zahra Kazemian $^{1} \cdot$ Mohammad Varzandeh $^{1} \cdot$ Sheyda Labbaf $^{1}{ }^{1}$
}

Received: 7 July 2020 / Accepted: 15 February 2021 / Published online: 12 March 2021

(C) The Author(s) 2021

\begin{abstract}
Bioactive glasses have attracted enormous attention in the field of biomaterials for dental and medical applications. Incorporation of antibacterial ions within BGs has been proved to be a promising approach to fortify their bactericidal character. In this study, homogenous BGs containing silver $(\mathrm{Ag})$ ions were synthesized by sol-gel method. Subsequently, the presence of the embedded ions were characterized by X-ray fluorescence (XRF) elemental analysis and energy dispersive X-ray (EDX) spectroscopy. Moreover, released ions were measured in simulated body fluid (SBF) and their antibacterial effectiveness was further verified using minimum bactericidal concentration (MBC) and minimum inhibitory concentration (MIC) tests. A crystalline hydroxyapatite layer was formed on the Ag-BG surfaces at day 5 approved by X-ray diffraction indicating the preserved bioactivity. The resultant uniform, mono-dispersed and dense nanoparticles show 19 great potential for a range of orthopedic and dental applications.
\end{abstract}

\section{Graphical Abstract}

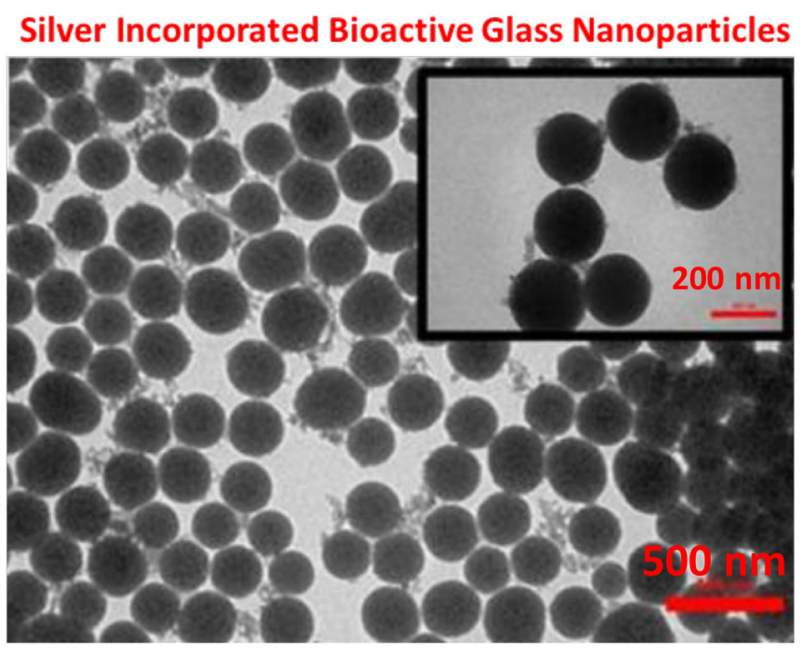

Supplementary information The online version contains supplementary material available at https://doi.org/10.1007/s10856021-06496-9.

Sheyda Labbaf

s.labbaf@iut.ac.ir

1 Department of Materials Engineering, Isfahan University of Technology, Isfahan 84156-83111, Iran

\section{Introduction}

The ion-dependent tunable biodegradability and osteogenic behavior of bioactive glasses (BGs) have made them ideal candidates for orthopedic applications [1-3]. Previous studies have shown the in vitro antibacterial activity of $\mathrm{SiO}_{2} 53 \%$ $\mathrm{Na}_{2} \mathrm{O} 23 \% \mathrm{CaO} 20 \%-\mathrm{P}_{2} \mathrm{O}_{5} 4 \%$ (S53P4) BG by increasing the $\mathrm{pH}$ of bacteria microenvironment and osmotic pressure [4] caused through the release of ionic dissolution products leading to the damaging of bacterial cell wall by BG sharp debris [5]. However, in-vivo blood flow and buffering system diminished this property [6]. Therefore, there has been a great 
shift towards multifunctional BG structures with an improved intrinsic antibacterial property [7]. The inspiring biological role of $\mathrm{BG}$ dissolution products such as $\mathrm{P}[8,9], \mathrm{Ca}[10]$, and Si [11, 12] on osteoblast proliferation, differentiation, and ECM mineralization is well known. However, through the utilization of BGs for in vivo applications, the high risk of infection still remains a challenge. Previous studies have shown that ions like $\mathrm{Cu}$ [13-15], $\mathrm{Zn} \mathrm{[16],} \mathrm{Ag} \mathrm{[17],} \mathrm{Ce} \mathrm{[18],}$ $\mathrm{Ga}$ [19], and $\mathrm{Mn}$ [20] have been incorporated into $\mathrm{BG}$ for combating the bacteria.

Amongst all, silver ion acts as an effective antibacterial agent via interaction with the thiol groups of proteins and cause DNA dysfunction in gram positive and gram negative bacterium [21]. Apart from that, using antibacterial silver nanoparticles itself cause toxicity by generating reactive oxygen species [22] and cause mitochondria dysfunction [23] for adjacent cells which has, hence, restricted its clinical application. Also, silver particle-specific antibacterial is negligible [24]. So, the researchers have chosen the $\mathrm{Ag}^{+}$ion dominantly against bacterium.

Many attempts have been made to incorporate Ag ions into the BG structure using sol-gel method [25] and molten salt ion exchange method [26]. Zhu et al. [17] investigated the role of amine modification on $\mathrm{Ag}^{+}$loading in mesoporous $58 \mathrm{~S}\left(\mathrm{SiO}_{2} \quad 58 \%-\mathrm{Na}_{2} \mathrm{O} \quad 33 \%-\mathrm{P}_{2} \mathrm{O}_{5} \quad 9 \%\right)$. They observed enhanced $\mathrm{Ag}^{+}$loading of $5.29 \%$ which resulted in improved antibacterial behavior after $768 \mathrm{~h}$ post testing. In a different study, Palza et al. [25] synthesized BG microparticles containing $\mathrm{Ag}^{+}$and $\mathrm{Cu}^{2+}$ ions using sol-gel method.. Minimum concentration of Ag-BG ( $1 \mathrm{mg} / \mathrm{ml}$ for $E$. coli and $3 \mathrm{mg} / \mathrm{ml}$ for $S$. mutans) was lower than $\mathrm{Cu}-\mathrm{BG}$ $(125 \mathrm{mg} / \mathrm{ml}$ for $E$. coli and $8 \mathrm{mg} / \mathrm{ml}$ for $S$. mutans) in minimum bactericidal concentration (MBC) testing.

In the current study, spherical and mono-dispersed submicron Ag containing bioactive glass particles are prepared through a simplified sol-gel method to evaluate its suitability for bone related applications. The uniform and monodispersed particles could have numerous biomedical application. BG nanoparticles could be directly injected into the defect site and could be internalized by cells for the local sustained delivery of inorganic therapeutic ions. The particles also have great potential to be incorporated within a polymeric matrix to create a nanocomposite scaffold for bone tissue engineering or be coated on a bio metallic substrate to increase corrosion resistance and enhance surface bioactivity.

\section{Materials and methods}

\subsection{Synthesis of nanoparticles}

Monodispersed BGs sub-micron particles were prepared by modifying our previous synthesis process [27].
Briefly, ethanol:deionized water with volumetric ratio of 9:1 was prepared. $100 \mu$ Lof tetraethylorthosilicate was added to $5 \mathrm{~mL}$ of the above-mentioned solvent and left for $20 \mathrm{~min}$ sonication before $5 \mathrm{ml}$ sodium hydroxide was added. $0.045 \mathrm{~g}$ and $0.11 \mathrm{~g}$ of calcium nitrate and silver nitrate were added, respectively with 45 min time intervals. Resultant particles were centrifuged and then dried in oven over night. Finally, the sintering procedure was applied at $600{ }^{\circ} \mathrm{C}$ which heating and cooling rate was $5^{\circ} \mathrm{C} / \mathrm{min}$ and $10^{\circ} \mathrm{C} / \mathrm{min}$.

\subsection{BG characterization}

The morphology of the synthesized NPs was analyzed by Scanning Electron Microscopy (SEM- PHILIPS XL30) and transmission electron microscopy (TEM, JEOL. Composition analysis was conducted using of the Energy Dispersive Spectroscopy (EDS) and X-ray fluorescence (XRF) techniques. Phases and crystallinity of the samples were characterized by X-ray diffraction (XRD, X'Pert Pro X-ray diffractometer, Phillips, Netherlands). Image J software was utilized to measure particle size.

\subsection{Bioactivity testing}

The apatite formation ability of $\mathrm{Ag}-\mathrm{BG}$ was assessed in accordance to our previous study [27]. First, the samples were soaked in the simulated body fluid (SBF) at $2 \mathrm{mg} / \mathrm{ml}$ concentration at $37^{\circ} \mathrm{C}$ for 1 and 3 days. The $\mathrm{pH}$ of the solution was assessed throughout the testing. At the end of each time point, particle was separated, washed and dried in oven at $40{ }^{\circ} \mathrm{C}$ overnight. XRD was conducted to characterize the formed apatite layer. To evaluate degradation through ionic release, inductively coupled plasma (ICP) was conducted.

\subsection{Antibacterial activity}

Antibacterial activity of Ag-BG NPs was assessed using minimum inhibitory concentration MIC and MBC tests. The assays were conducted against standard Staphylococcus aureus ATCC 6538 and Escherichia coli ATCC 25922 as gram-positive and gram-negative bacteria, respectively. A concentration range of 35-30,000 $\mu \mathrm{g} \mathrm{ml}^{-1}$ was selected. All tests were conducted in triplicates and according to clinical and laboratory standard institute (CLSI) [28].

\subsection{Cell culture}

The human osteoblast cells (MG63) were obtained from the Pasteur Institute (Iran) and were cultured in Dulbecco's modified eagle's medium-high glucose 12800 
(DMEM12800), fetal bovine serum, penicillin, streptomycin, glutamax, and trypsin/EDTA solutions were obtained from Gibco (Germany). Cells were seeded at a density of 10,000 cells/well in a 48 well/plate. Samples were heat-sterilized at $120^{\circ} \mathrm{C}$ for $2 \mathrm{~h}$ followed by UV sterilization and prepared at 100 and $250 \mu \mathrm{g} / \mathrm{ml}$ concentrations. Prior to cell exposure the resultant suspensions were sonicated for $15 \mathrm{~min}$ followed by vortex to ensure particle dispersion. At the end of each time point ( 1,3 , and 5 days) MTS reagent was added to each well and incubated for $3.5 \mathrm{~h}$ at $37^{\circ} \mathrm{C}$ and measured at $450 \mathrm{~nm}$ using a microplate reader (Bio-Rad, USA).

\section{Results and discussion}

Ag doped BG (Ag-BG) nanoparticles is presented in Fig. 1a,b. According to images, uniform and monodispersed particles have been synthesized using a facile processing method. Also, the nanoparticles exhibited more smooth and regular shape in comparison with the previous works [29]. An average particle size of $200 \pm 25 \mathrm{~nm}$ was obtained $(n=50)$, which is significantly smaller than a previous study where $400 \mathrm{~nm} \mathrm{Ag-}$ BG particles were produced [30]. Figure 1c confirms the presence of $\mathrm{Si}, \mathrm{Ca}$, and $\mathrm{Ag}$ in the $\mathrm{BG}$ particles. The XRD spectra in Fig. 1d show a broad peak within 15-30 corresponding to the glassy state of the particles. This is in good agreement to our previous studies [27, 31].

The accuracy of the Ag ion doping into the BG was further evaluated using XRF. Regarding to the XRF elemental analysis results in Table 1, the $\mathrm{SiO}_{2}, \mathrm{CaO}$, and $\mathrm{Ag}$ concentration of examined was found to be 74,24 , and $2 \mathrm{wt} \%$, respectively. The molar fraction resulted from XRF confirms the EDX results with some variations. In the other words by overlooking the oxygen fraction in EDX results the molar fraction of $\mathrm{Si}^{4+}, \mathrm{Ca}^{2+}$, and $\mathrm{Ag}^{+}$equals to $80,17.5$, and $2.5 \%$, which is close to the results emanated from XRF. This statement is now added to the revised manuscript.

Our observations suggest that BGs dissolve in SBF, changing the $\mathrm{pH}$ of the surrounding medium by releasing ionic products liberated from BG particulates. Dissolution from the BGs leads to a super-saturation of $\mathrm{Ca}$ ions in the SBF solution and subsequent re-precipitation of $\mathrm{Ca}$ and $\mathrm{P}$ rich crystals on their surface. Dissolution of the silica
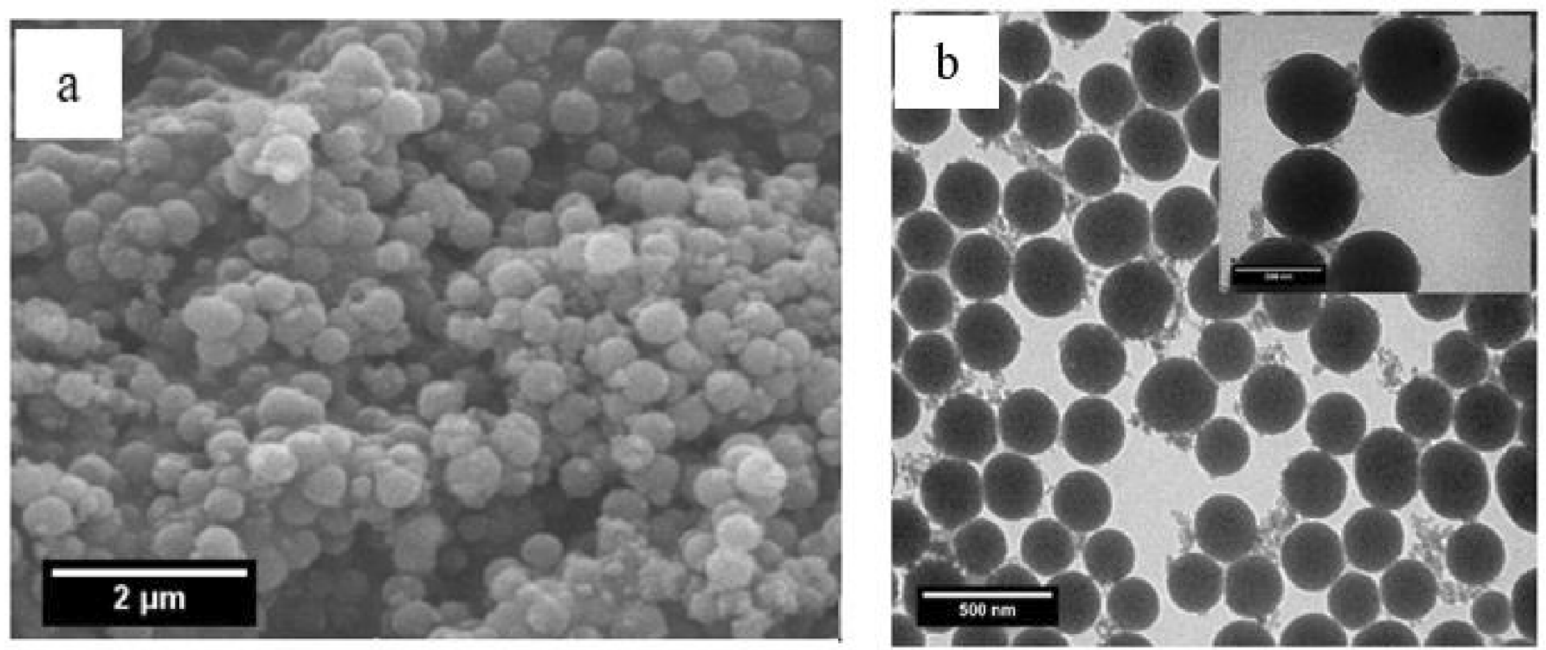

c
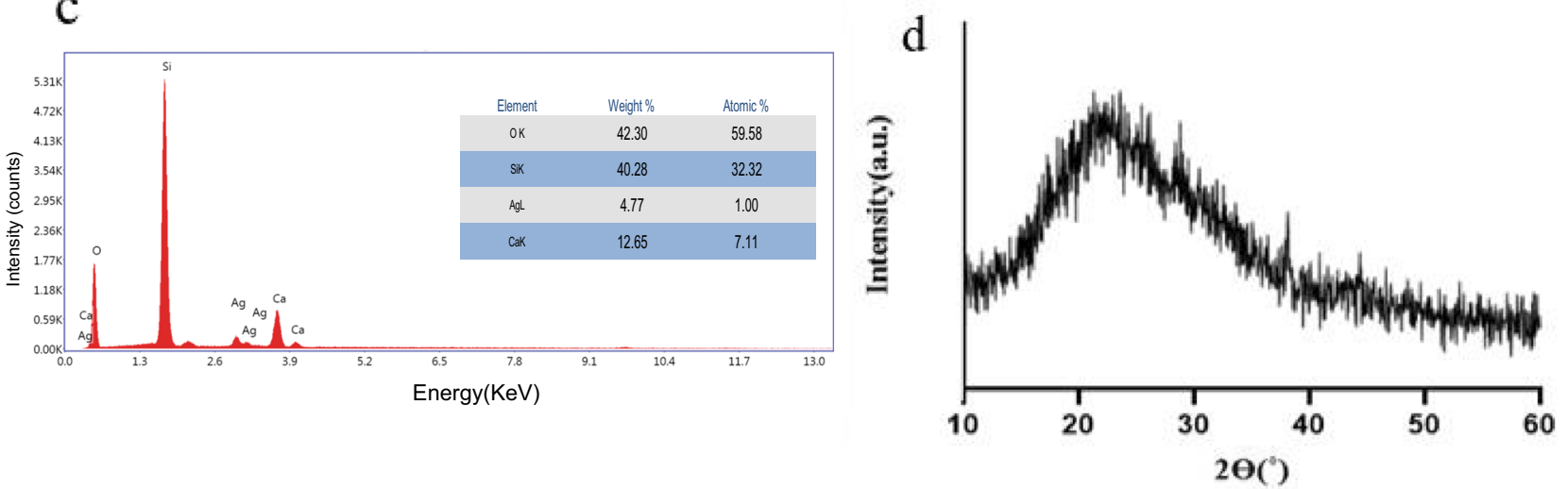

Fig. 1 a SEM and b TEM images (scale bar $500 \mathrm{~nm}$ and inset $200 \mathrm{~nm}$ ) of Ag-BG with inset showing a higher magnification image, c the corresponding EDS analysis, and $\mathbf{d}$ XRD pattern of particles calcinated at $600^{\circ} \mathrm{C}$ 
Table 1 XRF elemental analysis of as-prepared Ag-BG particles

\begin{tabular}{llll}
\hline Compound & $\mathrm{SiO}_{2}$ & $\mathrm{CaO}$ & $\mathrm{Ag}_{2} \mathrm{O}$ \\
\hline Concentration (\%wt) & 74 & 24 & 2 \\
\hline
\end{tabular}

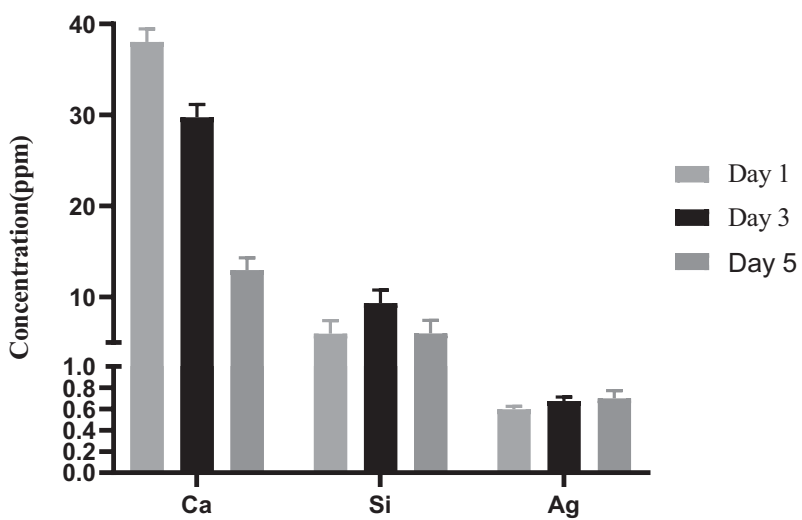

Fig. 2 ICP analysis of the Calcium $\left(\mathrm{Ca}^{2+}\right)$, Silicon $\left(\mathrm{Si}^{4+}\right)$, and Silver $\left(\mathrm{Ag}^{+}\right)$ions release in the medium containing $\mathrm{Ag}-\mathrm{BG}$ at day 1, 3, and 5

network (breaking Si-O-Si bonds) then occurs. $\mathrm{Ca}$ and $\mathrm{P}$ can combine in solution and deposit onto silanol bonds on the glass surface, nucleating a hydroxycarbonate apatite layer.

Sol-gel derived BGs are known to have a greater rate of bioativity, through dissolution and the release of ionic product, owed to their high surface and high level of surface $\mathrm{OH}$ groups. Here, the dissolution of $\mathrm{Ag}-\mathrm{BG}$ structures through ionic release study following immersion in SBF was evaluated by ICP following 1, 3, and 5 days (Fig. 2). Our observation suggests a supersaturation of $\mathrm{Ca}$ ions in the SBF solution, which subsequently results in re-precipitation of $\mathrm{Ca}$ and $\mathrm{P}$ (from SBF) crystals on $\mathrm{Ag}-\mathrm{BG}$ surface. The dissolution of $\mathrm{Si}-\mathrm{O}-\mathrm{Si}$ network then occurs, creating silanol bonds onto which $\mathrm{Ca}$ and $\mathrm{P}$ in the form of apatite can deposit. The Ag ion amount within solution has increased from day 1-3 similar to a previous report [17]. The maximum Ag ion release was in day 5, However, a decreasing trend in $\mathrm{Ca}$ was observed.

In order to prove the Ag-BG bioactivity, hydroxy apatite (HA) formation on their surface after SBF immersion was evaluated by the means of XRD and EDS. As illustarted in Fig. 3, XRD patterns are gradually transforming from amorphous structure to the crystalline structure [32]. The narrow peaks at $31.9,39$, and 48 illustrate the highly crystalline HA phase formation at 1 and 3 days. The peaks of HA deposition detected after 1 day, have sharpened by day 3. This is an important finding as it highlights the enhaced bioactivity rate of $\mathrm{Ag}$-BG nanoparticles compared to a previous study on Ag-BG [30].

The antibacterial activity of the Ag-BG particles against gram positive and gram negative bacteria was evaluated by
- $\mathrm{Ca}_{10}\left(\mathrm{PO}_{4}\right)_{6}(\mathrm{OH})_{2}$

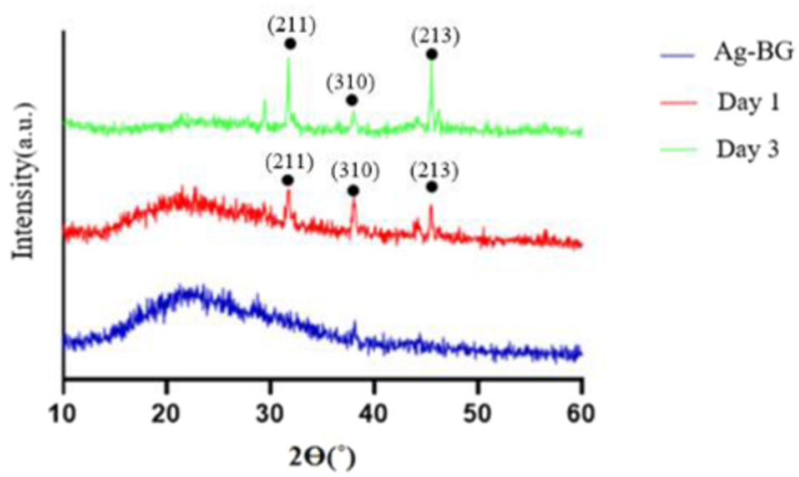

Fig. 3 a XRD patterns of the Ag-BG particles following immersion in $\mathrm{SBF}$ after at 1 and 3 days

Table 2 MBC and MIC antibacterial test of Ag-BG against Staphylococcus aureus and E.coli

\begin{tabular}{lll}
\hline Bacteria & MBC $(\mu \mathrm{g} / \mathrm{ml})$ & MIC $(\mu \mathrm{g} / \mathrm{ml})$ \\
\hline S. aureus ATCC 6538 & 134 & 134 \\
E.coli ATCC 25922 & 268 & 268 \\
\hline
\end{tabular}

MBC and MIC tests. The bactericidal and inhibitory concentration of the Ag-BG against s. Aureus was half of that of E. Coli. As shown in Table 2, the MBC and MIC concentration of the Ag-BG particles was $134 \mu \mathrm{g} / \mathrm{ml}$ and $268 \mu \mathrm{g} / \mathrm{ml}$, respectively. This concentration is moderately lower than the previous studies which provides higher efficiency [14]. The amorphous structure of the present study instead of crystalline structure, enhanced the available $\mathrm{Ag}$ ions for effective bactericidal activity [25, 29, 33].

Cell metabolic activity and consequently cell viability was assessed using MTS (Fig. 4). As can be seen, cell viability has not been affected by the addition of Ag-BG nanoparticles, except a reduction at a higher concentration of $250 \mu \mathrm{g} / \mathrm{ml}$, after 5 days of culture, is detected. This finding has previously been reported [14] for $\mathrm{SiO}_{2}-\mathrm{CaO} \mathrm{BG}$ nanoparticles and was attributed to the mechanism of calcium homeostasis by the mitochondria, hence influencing metabolic activity and cell viability results.

\section{Conclusion}

Monodisperse Ag-BG particles was successfully synthesized through a simple sol-gel method with simultaneous bioactivity and antibacterial behavior. The bioactivity of the Ag-BG was confirmed by XRD characterization of hydroxy-carbonate apatite layer formation on their surfaces following the immersion in SBF. Amount of released Ag ions in SBF have measured by ICP which was sufficient for 


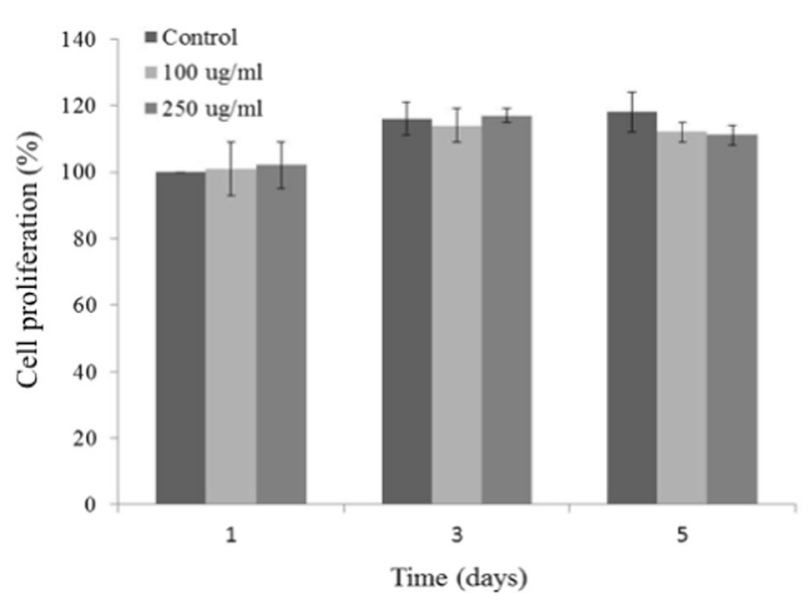

Fig. 4 MTS cell viability assay following 1,3, and 5 days for Ag-BG tested at 100 and $250 \mu \mathrm{g} / \mathrm{ml}$. The data represent the mean values \pm SD of two individual experiments each performed in triplicate and are normalized to the control of day 1

antibacterial activity as further evidenced by MBC and MIC tests. Particle did not inhibit the cellular growth pattern and were found to be non-cytotoxic.

\section{Compliance with ethical standards}

Conflict of interest The authors declare no competing interests.

Publisher's note Springer Nature remains neutral with regard to jurisdictional claims in published maps and institutional affiliations.

Open Access This article is licensed under a Creative Commons Attribution 4.0 International License, which permits use, sharing, adaptation, distribution and reproduction in any medium or format, as long as you give appropriate credit to the original author(s) and the source, provide a link to the Creative Commons license, and indicate if changes were made. The images or other third party material in this article are included in the article's Creative Commons license, unless indicated otherwise in a credit line to the material. If material is not included in the article's Creative Commons license and your intended use is not permitted by statutory regulation or exceeds the permitted use, you will need to obtain permission directly from the copyright holder. To view a copy of this license, visit http://creativecommons. org/licenses/by/4.0/.

\section{References}

1. Hench LL, Polak JMJS. Third-generation biomedical materials. 2002;295(5557):1014-7.

2. Rahmati M, Mozafari M. Selective contribution of bioactive glasses to molecular and cellular pathways. ACS Biomater Sci Eng. 2019.

3. Jones JR. Review of bioactive glass: from hench to hybrids. Acta Biomater. 2013;9(1):4457-86.

4. Stoor P, Söderling E, Salonen JIJAOS. Antibacterial effects of a bioactive glass paste on oral microorganisms. Acta Odontol. Scand. 1998;56(3):161-5.

5. Hu S. et al. Study on antibacterial effect of 45S5 Bioglassr ${ }^{\oplus}$. J. Mater. Sci.: Mater. 2009;20(1):281-6.
6. Xie ZP. et al. In vivo study effect of particulate Bioglassr ${ }^{\circledR}$ in the prevention of infection in open fracture fixation. J Biomed Mater Res B Appl Biomater. 2009;90(1):195-201.

7. Brokesh AM, Gaharwar AK. Inorganic biomaterials for regenerative medicine. ACS Appl Mater Interfaces. 2020.

8. Julien $M$. et al. Phosphate-dependent regulation of MGP in osteoblasts: role of ERK1/2 and Fra-1. J Bone Miner Res. 2009;24 (11):1856-68.

9. Ferraris S, et al. Bioactive materials: in vitro investigation of different mechanisms of hydroxyapatite precipitation. Acta Biomater. 2020;102:468-80.

10. Maeno S. et al. The effect of calcium ion concentration on osteoblast viability, proliferation and differentiation in monolayer and 3D culture. Biomaterials. 2005;26(23):4847-55.

11. Reffitt D. et al. Orthosilicic acid stimulates collagen type 1 synthesis and osteoblastic differentiation in human osteoblastlike cells in vitro. Bone. 2003;32(2):127-35.

12. Skallevold HE, et al. Bioactive glass applications in dentistry. Int J Mol Sci. 2019;20(23):5960.

13. Bari A. et al. Copper-containing mesoporous bioactive glass nanoparticles as multifunctional agent for bone regeneration. Acta Biomater. 2017;55:493-504.

14. Koohkan R. et al. Synthesis, characterization and in vitro bioactivity of mesoporous copper silicate bioactive glasses. Ceram. Int. 2018;44(2):2390-9.

15. Luo H, et al. One-pot synthesis of copper-doped mesoporous bioglass towards multifunctional $3 D$ nanofibrous scaffolds for bone regeneration. J Non-Cryst Solids. 2020;532:119856.

16. Sánchez-Salcedo $\mathrm{S}$. et al. In vitro antibacterial capacity and cytocompatibility of $\mathrm{SiO}_{2}-\mathrm{CaO}-\mathrm{P}_{2} \mathrm{O}_{5}$ meso-macroporous glass scaffolds enriched with ZnO. J. Mater. Chem. B 2014;2(30):4836-47.

17. Zhu H. et al. Preparation and antibacterial property of silvercontaining mesoporous $58 \mathrm{~S}$ bioactive glass. Mater Sci Eng C. 2014;42:22-30.

18. Goh Y-F. et al. In-vitro characterization of antibacterial bioactive glass containing ceria. Ceram. Int. 2014;40(1):729-37.

19. Pourshahrestani S. et al. Gallium-containing mesoporous bioactive glass with potent hemostatic activity and antibacterial efficacy. Mater. Chem. b. 2016;4(1):71-86.

20. Nawaz Q, et al. Synthesis and characterization of manganese containing mesoporous bioactive glass nanoparticles for biomedical applications. J Mater Sci: Mater Med. 2018;29(5):64.

21. Feng QL. et al. A mechanistic study of the antibacterial effect of silver ions on Escherichia coli and Staphylococcus aureus. J Biomed Mater Res. 2000;52(4):662-8.

22. Castiglioni S. et al. Silver nanoparticles in orthopedic applications: new insights on their effects on osteogenic cells. Nanomat. 2017;7(6):124.

23. Maurer L, Meyer JJESN. A systematic review of evidence for silver nanoparticle-induced mitochondrial toxicity. Environ. Sci. 2016;3(2):311-22.

24. Xiu Z-M. et al. Negligible particle-specific antibacterial activity of silver nanoparticles. Nano Lett. 2012;12(8):4271-5.

25. Palza H. et al. Designing antimicrobial bioactive glass materials with embedded metal ions synthesized by the sol-gel method. $\mathrm{J}$ Mater Sci Eng C. 2013;33(7):3795-801.

26. Newby P. et al. Ag-doped 45S5 Bioglassr ${ }^{\circledR}$-based bone scaffolds by molten salt ion exchange: processing and characterisation. $\mathrm{J}$ Mater Sci Mater Med. 2011;22(3):557-69.

27. Tsigkou O. et al. Monodispersed bioactive glass submicron particles and their effect on bone marrow and adipose tissue-derived stem cells. Adv Healthc Mater. 2014;3(1):115-25.

28. Clinical and L.S.I.J.A. standard, Methods for dilution antimicrobial susceptibility tests for bacteria that grow aerobically. 2006. 26:14-16. 
29. Gupta N. et al. Effects of transition metal ion dopants ( $\mathrm{Ag}, \mathrm{Cu}$ and $\mathrm{Fe}$ ) on the structural, mechanical and antibacterial properties of bioactive glass. Colloid and surfaces. 2018;538:393-403.

30. El-Rashidy AA, et al. Preparation and in vitro characterization of silver-doped bioactive glass nanoparticles fabricated using a solgel process and modified Stöber method. J Non-Cryst Solids. 2018;483:26-36.
31. Labbaf S. et al. Spherical bioactive glass particles and their interaction with human mesenchymal stem cells in vitro. Biomaterials. 2011;32(4):1010-8.

32. Rabiee SM, et al. Effect of ion substitution on properties of bioactive glasses: a review. Ceram Int. 2015;41(6):7241-51.

33. Lee J-H. et al. Drug/ion co-delivery multi-functional nanocarrier to regenerate infected tissue defect. Biomaterials. 2017;142:62-76. 